\author{
Lenka Abrinkova*, Olga Orosová, Saul neves De Jesus, \\ Beata Gajdošová \& Maria Bacikova-Sleskova
}

\title{
RESILIENCE FACTORS, THE SCHOOL-BASED UNIVERSAL PREVENTION PROGRAM 'UNPLUGGED' AND HEALTHY BEHAVIOR AMONG EARLY ADOLESCENTS**
}

(Received: 9 September 2020; accepted: 31 July 2021)

The paper investigates the role of the internal asset (IA), perceived external resources (PER) of resilience, and the school-based universal prevention program known as 'Unplugged' in explaining persistent healthy behavior among early adolescence. A sample of 425 adolescents was collected in a repeated measure design study with a baseline (T1) and a six-month follow-up (T2) after the Unplugged implementation. Persistent healthy behavior was assessed by a change in the cumulative index of substance use created by combining alcohol use and cigarette smoking in the past 30 days and their change between T1 and T2. Four categories were created: non-users, permanent users, new users and ex-users. A multinominal logistic regression revealed that non-users were more likely to show higher self-esteem when compared to permanent users. Females had a higher probability of being non-users than either being permanent users or new users. Moreover, Unplugged intervention increased the probability of being a non-user rather than a new user. Regarding PER of resilience, non-users were more likely to have higher home support, prosocial peers, and school connectedness compared to permanent users. Non-users were also more likely to have higher levels of prosocial peers compared to new users. In summary, higher self-esteem, home support, prosocial peers and school connectedness are associated with persistent healthy behavior. To maintain this persistent healthy behavior, the school-based universal prevention program Unplugged has been effective; thus internal assets and external resources of resilience, and prevention program Unplugged, play an important role in the absence of alcohol or cigarette use in early teenage years.

Key words: adolescence; alcohol use; cigarette smoking; resilience; prevention programs; Unplugged

* Corresponding author: Lenka Abrinková, MSc (Ms), Department of Psychology Faculty of Arts, P.J.Safarik University, Moyzesova 9, 040 59, Kosice, Slovakia; lenka.abrinkova@student.upjs.sk.

** Funding: This work was supported by Research and Development support Agency under the contract No. APVV15-0662 and VEGA 1/0371/20. 


\section{Introduction}

The period of early adolescence stands as a period of significant changes in human life. The transition from childhood to adolescence is accompanied by biological, social, and emotional changes (DiClEMENTE et al. 2013). Social pressure increases, changes in health behavior occur and new adaptation skills are in development. It is also a risk period for an early onset of substance use which can set off deviant trajectories for young people in their lives and even lead to long term disabilities (CASTELlanOs-RYAN et al. 2013). Identification of protective personality factors that can be strengthened, and in environment factors which are accessible for adolescents, can bring forth a broader insight into what is really available for early adolescents and what can be done to promote the protective factors, eliminate the risks, and remain healthy. Moreover, various prevention programs aim to prevent young adolescents from engaging in risk behavior or at least delay the onset to a later life period and enhance positive and healthy development.

Past research strongly suggests that alcohol use and cigarette smoking are consistently the most prevalent drugs used among adolescents (WHO 2013; ESPAD 2016). Data from the ESPAD study show that generally $47 \%$ of respondents reported alcohol use at the age of 13 or younger (in Slovakia 63\%), while 23\% of respondents reported cigarette smoking at the age of 13 or younger (in Slovakia 36\%) (ESPAD 2016). This indicates that alcohol is the first drug of choice to use among adolescents in Europe. However, the earlier the age of the onset of substance use, the higher the probability of a negative effect in the future regarding mental health problems (Poudel \& Gautam 2017) or dependence on drugs (King \& Chassin 2007).

Although the studies of individual substance use (typically alcohol, tobacco, or marihuana) provide useful information, in the past few decades, the research shifted from an individual risk behavior research to multiple substance use research (KoKKeVI et al. 2014; LIPPERMAN-KreDA et al. 2017). Less research activity is focused on a cumulative index of substance use which combines alcohol use and cigarette smoking. The reason for combining the two most frequent risk behaviors in adolescence is the fact that they have common factors which enhance addictions starting in adolescence (NowAK et al. 2018). It is necessary to investigate the first signs of substance use in early adolescence, which occurs mostly through using alcohol or cigarettes (Poudel \& GAUTAM 2017). A lot of research has been done regarding personality and environmental risk factors associated with substance use in early age. The development of prevention models based on the resilience model have enabled a shift in focus from risk factors to positive factors of adolescents' healthy development and contributed to a growing research in resilience theory (VAN BReda 2018; Masten 2007; Masten 2014).

The resilience framework implies the focus on positive outcomes and their antecedents, favoring primary prevention which could delay the period of onset or 
prevent the use itself (LUTHAR et al. 2000). From this broader perspective, resilience can be understood as the ability of the system to successfully adapt to the challenges that threaten the function, survival or future development of the system (MASTEN 2014). The process oriented approach views resilience as a dynamic process rather than a personality trait bounded by the body and mind of an individual (LUTHAR et al. 2000; FERGUS \& Zimmerman 2005) and represents an active participation in processes that enable positive development outcomes to happen. Resilience is therefore not only a quality of an individual but reflects how well the social and physical environment (home, school, family, friends) promotes access to internal and external resources such as supportive relationships, strong identity, material needs and meaningful participation (UNGAR 2004).

The examination of innate resilience characteristics has had a dominant position in the field of resilience research. This can be seen in focusing on factors related to self-system, for example: self-regulation (CADIMA et al. 2006; WiLls et al. 2008) and self-esteem (KoKKEVI et al. 2014; DonNELLY et al. 2008), which possess protective potential. However, protective resources can also be detected in environmental systems in which child development is set, such as families, classes, or schools that are labeled as social environments (Van BREDA 2018). Therefore, environmental resilience promoting factors in early adolescence can be divided into four broad levels: family, school, peer group and community (RUDZINSKI et al. 2017; HoDDER et al. 2016) which are rapidly changing during the transition period from childhood to adolescence. The influence of peers increases during adolescence (GAERTNER et al. 2010), parents' influence decreases but remains an important factor in adolescent development (KUNG \& FARRELL 2000), and schools and communities become primary social contexts outside the home where a wide range of peer and social interactions take place (Institute of Medicine and National Research Council 2011). It is crucial that adolescents acquire support and are actively involved in all the mentioned environmental levels for the health behavior promoting effect. Meaningful participation may serve as social control, keeping adolescents away from substance use, because their time and energy would be already committed in socially approved activities, extracurricular activities and decision making (OsGood et al. 1996). Moreover, support across different kinds of environments is positively associated with non or small amounts of substance use, and it is seen as a protective factor (HoDDER at al. 2016). However, it should be crucial to acknowledge the adolescents' perception of their environment rather than how it may objectively appear. It is precisely the perception of possible support and meaningful participation in the environment that can be protective against risk behavior.

The idea behind the umbrella approach of resilience sheltering internal factors and external resources is to contribute to healthy outcomes among youth (BENARD 2004; BENARD \& SLAdE 2009). Several theories and models have been introduced to understand resilience from the environmental perspective to emphasize the sur- 
roundings such as socio-ecological model (BRONFENBRENnER 1979), or the PIE - Person in Environment model (Van BREDA 2018). These models consider the complex interplay between personality and environment in which adolescents live. The ultimate goal of the research in resilience theory is to enhance the protective factors and to better understand determinants of substance use with the intention to enrich prevention strategies and bring valued insight of what youths actually have in their hands, in their minds, and in their surroundings, and most importantly what can be improved.

Besides the identification of resilience factors that contribute to healthy behavior, universal school-based prevention programs represent an opportunity to reduce the prevalence of substance use or delay it to later periods. Early adolescents are often targeted as a group for school-based drug prevention programs based on the strategy that the earlier exposure to prevention the better. One of the prevention programs regarding substance use which was specifically created to meet the demand for a prevention program in Europe is the Unplugged program. Unplugged aims to prevent the use of alcohol, tobacco, marihuana and other legal and illegal drugs among early adolescents. Its main goal is to prevent or delay substance use in young people regardless of their risk profile and the environment from which they come from (BoHrN et al. 2008). The effectiveness of Unplugged has been tested regarding behavioral indicators in various countries, including Slovenia (ALESINA et al. 2014) particularly on reduction of alcohol use, cigarette smoking and drunkenness; Czech Republic (GABRHELIK et al. 2012) on reduction of current tobacco use and marihuana use; Brazil (SANCHEZ et al. 2016) on reduction of marihuana use and binge drinking. Unplugged indicated persistent positive effects in reducing alcohol consumption and cannabis use among early adolescents within 18 months (FAGGIANO et al. 2010) and the prevalence of smoking and drunkenness two years after the program implementation (MIOvskÝ et al. 2012).

\section{Aim}

Based on previous findings, the relationship between internal assets, perceived external resources of resilience and healthy behavior has been widely established while little attention has been paid to this issue within the Unplugged program. The nature of these relationships and changes of healthy behavior within Unplugged deserve more attention. Thus, the main aim of the present study is to explore whether internal assets and perceived external resources of resilience within Unplugged can predict health behavior represented by a change in cumulative index of substance use. 


\section{Design and measurements}

\subsection{Research design}

The school-based universal prevention program Unplugged was created as a part of the Eu-DAP (European Drug Abuse Prevention) program (GABRHELIK et al. 2012). The program has been designed for adolescents within the age of 12-14 years and has been also implemented in the following countries: Italy, Belgium, Spain, Austria, Sweden, Greece and Germany (BoHRN et al. 2008). The theoretical background of the Unplugged program lies in the CSI model (Comprehensive Social Influence model) and the KAB model (Knowledge - Abilities - Behavior). It is based on the combination of prevention methods that are focused on personal and social skills development and the corrections of normative beliefs regarding substance use.

The program is divided into 12 lessons, which include three content units: Information and Attitudes, Intrapersonal Skills, and Interpersonal Skills. During the program, students acquire social, emotional, and personality skills, critical-thinking skills, effective communication skills, decision-making skills, problem-solving skills, self-regulatory skills, and other interpersonal skills through development of group dynamics and social interaction (Miovský et al. 2012). Regarding the methodological material, the program contains a handbook for teachers, a workbook for students, and cards.

The Unplugged program was implemented by teachers who completed a threeday training course. The implementation did not follow a strict time plan but depended on the availability and resources of each school individually. The implementation took place in the primary schools in the Slovak Republic. The teachers' training course focused on the program implementation process, interactive work with pupils, and the methodology necessary to work with social competences.

\subsection{Sample}

The evaluation of Unplugged has been conducted within an experimental design as a repeated measure study with baseline (T1) and six month follow-up (T2).

School selection was conducted with the aim to obtain a representative sample with respect to regional, town size characteristics in order to meet the requirements of the project under which the Unplugged program had been implemented (for more information see BERINŠTEROvá et al. 2015).

In total, 12 primary schools participated in the study (six schools in the experimental group and six in the control group). The schools were randomly selected and assigned to either the experimental or the control group. Seventh-grade students from every school participated in the research. The study obtained the local university 
Ethics committee approval. Parents were informed about the study and could opt out if they disagreed with their child's participation.

Within this current study, data from the baseline (T1) and the six month follow-up (T2) have been analyzed. Only participants who completed both questionnaires at $\mathrm{T} 1$ and at T2 had been included in the analysis. Ultimately, 425 early adolescents participated in the research ( $57 \%$ in the experimental group). The mean age at baseline was 13.50 , SD 0.67 ( $\min 13-\max 16) ; 48 \%$ males. As the participation in the research was anonymous, an identification code was used to pair respondents across the waves. Due to some errors in the identification code as well as the absence due to sickness of some respondents, a total number of $21.6 \%$ of respondents could not be paired.

The experimental group and the control group were compared and no difference in alcohol use and cigarette smoking in the previous 30 days was found between paired respondents and unpaired respondents in both groups. We also checked the differences in the background characteristics, such as gender for both groups, and found no differences. The Mann-Whitney U test was used to check for differences in all independent variables between paired and unpaired respondents, and differences were found only in the experimental group in the variables of Home meaningful participation and School meaningful participation, which were higher among the unpaired respondents.

\subsection{Measures}

Change in cumulative index of substance use was created by computing two variables that represented alcohol use (e.g., 'On how many occasions (if any) have you had any alcoholic beverage to drink during the last 30 days?') and cigarette smoking (e.g., 'On how many occasions (if any) have you smoked cigarettes during the last 30 days?') with possible answers: $0,1,2-4,5$ or more. We dichotomized the variables separately at T1 and T2 into 'no alcohol use/no cigarette use $=0$ ' (those who did not drink alcohol or smoke cigarettes in the past 30 days) versus 'present alcohol use/cigarette use $=1$ ' (others). Dichotomized variables were computed separately at T1 and T2 into 'no risk behavior' $=0$ (absence of alcohol use and cigarette smoking) and 'present risk behavior' $=1$ (alcohol use or cigarette smoking) and the variable labeled 'cumulative index of risk behavior' was created. After creating a risk behavior cumulative index separately for $\mathrm{T} 1$ and $\mathrm{T} 2$, we generated the variable called 'change in prevalence of risk behavior cumulative index' representing the difference in risk behavior between T1 and T2. Four groups were created $(0=$ non users - no risk behavior at $\mathrm{T} 1$ and $\mathrm{T} 2,1=$ persistent users - present risk behavior at $\mathrm{T} 1$ and $\mathrm{T} 2,2=$ new users - no risk behavior at $\mathrm{T} 1$ but present risk behavior in $\mathrm{T} 2,3=$ ex users - present risk behavior at $\mathrm{T} 1$ and but no risk behavior at T2). 
Only $1.9 \%$ of adolescents in the control group and $4.0 \%$ in the experimental group at $\mathrm{T} 1$ exhibited a concurrent polydrug use in the previous 30 days. Due to the very low prevalence of risk behavior, it was not possible to conduct valid analyses. Thus, the subgroups: permanent users, new users, and ex users are generated based on either alcohol use or cigarette smoking at $\mathrm{T} 1$ and $\mathrm{T} 2$. The number of participants in every group can be found in Table 1 .

Table 1

The number of participants according to change in cumulative index of substance use

\begin{tabular}{cccc}
\hline $\begin{array}{c}\text { Change in cumulative index } \\
\text { of substance use }\end{array}$ & Control group & Experimental group & Total \\
\hline Non-users & $132(65.7 \%)$ & $183(67.8 \%)$ & $315(66.9 \%)$ \\
Permanent users & $18(9.0 \%)$ & $38(14.1 \%)$ & $56(11.9 \%)$ \\
New users & $28(13.9 \%)$ & $22(8.1 \%)$ & $50(10.6 \%)$ \\
Ex users & $23(11.4 \%)$ & $27(10.0 \%)$ & $50(10.6 \%)$ \\
\hline
\end{tabular}

The RYDM (Resilience and Youth development module) (Constantine et al. 1999; FURLONG et al. 2009) measures external resources as aspects of resilience with a four-point Likert type scale (from $1=$ not at all true to $4=$ very much true). A higher score represents a higher level of resilience. In the present study, we focus on the nine external resources that support development and resilience.

By answering 38 questions, the respondents expressed their own perception of three protective factors - supportive relationships, high expectations, and opportunities for meaningful participation across the environment where a young person moves: home, school, community and peer group. HANSON and KIM (2007) found that the items from the subscales caring relationship and high expectations form a single factor which they called 'Support'. This study focuses on the School Support (e.g., 'At my school, there is a teacher or some other adult who really cares about me'), School Meaningful Participation (e.g., 'At school I help decide things like class activities or rules'), Home Support (e.g., 'At my home there is a parent that cares about my school'), Home Meaningful Participation (e.g., 'At home I participate in decision making with my family'), Community Support (e.g., ' Outside of my home and school, there is an adult who really cares about me'), Community Meaningful Participation (e.g., 'Outside of my home and school, I do these things: I am part of clubs, sports teams, church/temple, or other group activities'), Peer Support (e.g., 'I have a friend about my own age who really cares about me'), Prosocial Peers (e.g., 'My friends try to do what is right') and School Connectedness (e.g., 'I feel 
like I am part of this school'). Cronbach's alpha was calculated for the whole scale $(\alpha=0.92)$ as well as for the individual subscales $(\alpha=0.87 ; \alpha=0.67 ; \alpha=0.85 ; \alpha$ $=0.81 ; \alpha=0.93 ; \alpha=0.68 ; \alpha=0.90 ; \alpha=0.60 ; \alpha=0.81)$, yielding generally a very high consistency.

The Self-Esteem scale (RoSEnBERG 1979) consists of ten items (e.g., 'On the whole, I am satisfied with myself'). Respondents answer individual questions on a four-point Likert type scale (from $1=$ strongly disagree to $4=$ strongly agree). A higher score represents a higher level of self-esteem. The Cronbach's alpha was 0.76 .

The Self-control scale (FINKENAUER et al. 2005) originally consisted of 11 items (e.g., 'I have a hard time breaking a bad habit'). Respondents answer on a five-point Likert type scale (from $1=$ never to $5=$ always). A higher score indicates a higher level of self-control after re-coding. The shortened version of the questionnaire was used due to the low level of internal consistency. Cronbach's alpha of the shortened version was 0.66 .

\subsection{Statistical analyses}

All data were analyzed using the statistical software package IBM SPSS Statistics, version 21 for Windows.

A T-test was performed to address gender differences in all independent variables. Before exploring the association, we checked the model fit. The variance inflation factor diagnostics found that multicollinearity among the predictors was not a concern. The linear relationship between predictors and the logit of the outcome variable was proofed as well as the independence of errors due to the dispersion parameter $\varphi$ (FIELD 2009).

Then we assessed the association between internal assets and perceived external resources of resilience at $\mathrm{T} 2$ as possible factors influencing change in cumulative index of substance use by using multinominal logistic regression separately for internal assets and for the perceived external resources of resilience. In both regression models, the effect of gender and Unplugged participation was explored. As a reference category the 'non-users' were used.

\section{Results}

The descriptive characteristics of the independent variables (internal assets and perceived external resources of resilience) for the control and experimental group at $\mathrm{T} 2$ are presented in Table 2. 
Table 2

Descriptive characteristics of the studied variables in $\mathrm{T} 2$

\begin{tabular}{|c|c|c|c|c|c|c|}
\hline & \multicolumn{2}{|c|}{ Control group } & \multicolumn{2}{|c|}{ Experimental group } & \multirow[t]{2}{*}{$t / u$} & \multirow[t]{2}{*}{ Cohen's d } \\
\hline & Mean & $\mathrm{SD}$ & Mean & $\mathrm{SD}$ & & \\
\hline Self-esteem & 2.77 & 0.50 & 2.66 & 0.46 & $2.73 *$ & 0.22 \\
\hline Self-control & 3.30 & 0.62 & 3.21 & 0.58 & 1.54 & 0.15 \\
\hline School Support & 2.83 & 0.85 & 2.71 & 0.79 & 1.66 & 0.14 \\
\hline School Meaningful Participation & 2.56 & 0.83 & 2.50 & 0.80 & 124555.00 & 0.07 \\
\hline Home Support & 3.40 & 0.65 & 3.37 & 0.64 & 114911.00 & 0.04 \\
\hline Home Meaningful Participation & 3.08 & 0.88 & 3.11 & 0.78 & -0.37 & -0.03 \\
\hline Community Support & 2.84 & 1.03 & 2.92 & 0.96 & -0.89 & -0.08 \\
\hline Community Meaningful Participation & 2.99 & 0.92 & 2.97 & 0.82 & 0.26 & 0.02 \\
\hline Peer Support & 2.99 & 1.05 & 3.20 & 0.84 & $-2.37 *$ & -0.22 \\
\hline Prosocial Peers & 2.61 & 0.67 & 2.56 & 0.66 & 0.85 & 0.07 \\
\hline School connectedness & 3.60 & 0.90 & 3.46 & 0.83 & 1.74 & 0.16 \\
\hline
\end{tabular}

$* \mathrm{p}<.05, * * \mathrm{p}<.0$.

Table 2 shows that T-test was used to explore the differences in independent variables at T2 based on the participation in Unplugged. Home Support and School Meaningful Participation were not normally distributed, and as a result, Mann-Whitney U test was used.

The analysis has shown that significant differences existed between the participants in the control and the experimental group in Self-esteem and Peer support. The mean score in self-esteem was statistically significantly higher in the control group, while peer support stood higher in the experimental group. However, the effect size (Cohen) showed low values. 


\subsection{Internal assets of resilience}

Table 3

Change in cumulative index of substance use in association with internal assets, multinominal logistic regression in $\mathrm{T} 2$

\begin{tabular}{|c|c|c|c|}
\hline & \multirow[b]{2}{*}{$O R$} & \multicolumn{2}{|c|}{$95 \%$ C.I. for $\operatorname{EXP}(B)$} \\
\hline & & Lower & Upper \\
\hline \multicolumn{4}{|c|}{ Permanent users } \\
\hline T2 Self-esteem & 0.474 * & 0.243 & 0.925 \\
\hline T2 Self-control & 0.705 & 0.450 & 1.105 \\
\hline Gender & $0.535^{*}$ & 0.295 & 0.971 \\
\hline Program Unplugged & 1.364 & 0.736 & 2.528 \\
\hline \multicolumn{4}{|c|}{ New users } \\
\hline T2 Self-esteem & 0.530 & 0.262 & 1.074 \\
\hline T2 Self-control & 0.681 & 0.425 & 1.090 \\
\hline Gender & $0.521^{*}$ & 0.279 & 0.972 \\
\hline Program Unplugged & $0.513^{*}$ & 0.277 & 0.949 \\
\hline \multicolumn{4}{|c|}{ Ex users } \\
\hline T2 Self-esteem & 0.513 & 0.256 & 1.028 \\
\hline T2 Self-control & 0.879 & 0.553 & 1.396 \\
\hline Gender & 0.625 & 0.338 & 1.157 \\
\hline Program Unplugged & 0.773 & 0.420 & 1.423 \\
\hline
\end{tabular}

Reference group: non-users, males, control group

$\mathrm{x}^{2}=32.179(\mathrm{df}=12, \mathrm{p}<0.001)$

$* \mathrm{p}<.05, * * \mathrm{p}<.01$.

Two separate multinominal regression models were created to determine the association between the change in the cumulative index of substance use and (1) internal assets of resilience, and (2) the perceived external resources of resilience.

Table 3 shows the results of the multinominal regression analyses with internal assets of resilience including self-esteem and self-control, gender, and program Unplugged participation. Non-users served as the reference category to which the 
three other groups were compared. The regression model was statistically significant $\mathrm{X}^{2}=32.179(\mathrm{df}=12, \mathrm{p}<0.001)$, and explained between $6.6 \%$ (Cox \& Snell R square) and $7.6 \%$ (Nagelkerke $\mathrm{R}$ squared) of variance in change in cumulative index of substance use.

Non-users vs. Permanent users: Relative to children in the non-user group, children in the permanent user group were more likely to have a lower self-esteem (OR 0.474; 95\% CI $0.243-0.925$ ). Regarding gender, being a female reduces the likelihood of being in the permanent user group (OR 0.535; 95\% CI $0.295-0.971$ ).

Non-users vs New users: Participation in Unplugged reduces the likelihood of being a new user $(\mathrm{OR}=0.513 ; 95 \%$ CI $0.277-0.949)$. Regarding gender, being a female reduces the likelihood of being in the permanent user group $(\mathrm{OR}=0.521$; $95 \%$ CI $0.279-0.972$ ).

Non-users vs Ex-users: No statistically significant differences were found.

\subsection{External resources of resilience}

Table 4

Cumulative index of substance use in association with external resources of resilience, multinominal logistic regression in $\mathrm{T} 2$

\begin{tabular}{llll}
\hline & & \multicolumn{2}{c}{$95 \%$ C.I. for EXP $(B)$} \\
\cline { 3 - 4 } & OR & Lower & Upper \\
\hline Permanent users & & & \\
T2 School Support & 0.768 & 0.481 & 1.225 \\
T2 School Meaningful Participation & 1.244 & 0.778 & 1.989 \\
T2 Home Support & $\mathbf{0 . 5 9 8}$ & 0.358 & 0.999 \\
T2 Home Meaningful Participation & 0.896 & 0.558 & 1.439 \\
T2 Community Support & 1.398 & 0.957 & 2.041 \\
T2 Community Meaningful Participation & 0.950 & 0.633 & 1.426 \\
T2 Peer support & 1.223 & 0.829 & 1.803 \\
T2 Prosocial Peers & & 0.329 & 0.919 \\
T2 School connectedness & $\mathbf{0 . 5 5 0}$ & 0.381 & 0.844 \\
Gender & $\mathbf{0 . 5 6 7}$ & 0.294 & 1.166 \\
Program Unplugged & 0.586 & 0.793 & 3.019
\end{tabular}


New users

T2 School Support

T2 School Meaningful Participation

T2 Home Support

T2 Home Meaningful Participation

T2 Community Support

T2 Community Meaningful Participation

T2 Peer support

T2 Prosocial Peers

T1 School connectedness

Gender

Program Unplugged

T2 School Support

T2 School Meaningful Participation

T2 Home Support

T2 Home Meaningful Participation

T2 Community Support

T2 Community Meaningful Participation

T2 Peer support

T2 Prosocial Peers

T2 School connectedness

Gender

Program Unplugged
0.787

1.205

0.887

1.060

1.040

0.829

1.323

0.370

0.741

0.623

0.586

Ex users

1.155

0.595

0.915

0.964

0.838

1.223

1.224

0.931

0.748

0.809

0.717
0.478

0.738

1.295

1.970

0.497

1.584

0.640

1.757

0.712

1.269

1.828

0.635

1.153

1.280

1.142

0.300

1.948

1.012

1.645

1.585

1.175

1.892

1.822

1.609

1.160

1.632

0.401

1.365

Reference group: non-users, males, control group

$\mathrm{x}^{2}=76.550(\mathrm{df}=33, \mathrm{p}<0.001)$

$* \mathrm{p}<.05, * * \mathrm{p}<.01$. 
Table 4 shows the results of the second multinominal regression analysis with perceived external resources of resilience, gender, Unplugged participation and the dependent variable. Non-users served as the reference category to which the three other groups were compared. The regression model was statistically significant $\mathrm{X}^{2}$ $=76.550(\mathrm{df}=33, \mathrm{p}<0.001)$ and explained between $16.1 \%(\mathrm{Cox} \&$ Snell R square $)$ and $18.6 \%$ (Nagelkerke $\mathrm{R}$ squared) of variance in change in cumulative index of substance use.

Non-users vs. Permanent users: Relative to adolescents in the non-users group, children in the permanent users group were more likely to have a lower level of home support (OR 0.598; 95\% CI 0.358 - 0.999), school connectedness (OR 0.567; $95 \%$ CI $0.381-0.844$ ) and prosocial peers (OR 0.550; 95\% CI $0.329-0.844$ ).

Non-users vs New users: Relative to children in the non-user group, children in the new users group were more likely to have a lower level of prosocial peers (OR 0.370; 95\% CI $0.216-0.635$ ).

Non-users vs Ex-users: No statistically significant differences were found.

\section{Discussion}

This study's principal goal was to examine the role of the internal assets and perceived external resources of resilience in explaining persistent healthy behavior among early adolescents represented by change in cumulative index of risk behavior, and to explore whether gender and participation in Unplugged contributed to it.

Using multinominal logistic regression, we examined two internal assets of resilience associated with substance use among early adolescents: self-esteem and self-control at T2. Higher self-esteem was significantly associated with higher probability of being a non-user early adolescent. Our results are in accordance with the research showing that self-esteem is a key determinant of substance use but also of other antisocial behavior. A recent study has confirmed that if adolescents with higher self-esteem used alcohol, cigarettes, or marihuana, it was much lower when compared to adolescents with lower self-esteem (ZAMBOANGA et al. 2009). The data from BASUS (British Columbia Adolescents Substance Use Surveys) discovered that an increase of a point in Rosenberg Self-Esteem Scale reduced the odds of initiation alcohol use by $3 \%$, tobacco use by $9 \%$ and marihuana use by $7 \%$ among 8 and 9 grade students (RICHARDSON et al. 2013). However, our results do not confirm previous findings regarding self-control as protective factors regarding substance use (MofFITT et al. 2011; GRIFFIN \& BotvIN 2010) but these studies have mostly examined internal assets separately. As we conducted research where we examined two independent and strong internal assets simultaneously within the program Unplugged, we assumed that this could be the reason behind our results. Moreover, early adolescence is a period of significant social pressure and thus 
self-control itself may not play such a significant role in substance use compared to self-esteem.

Then, we examined the nine perceived external resources of resilience. The result showed that adolescents with higher home support, prosocial peers and school connectedness were more likely to be non-users than permanent users with the strongest effect seen in the resource prosocial peers. In addition, the higher level of prosocial peers had a protective effect on becoming a new user as well.

School connectedness is an essential protective environmental factor for substance use as well as other kinds of different risk behavior (WEATHERSON et al. 2018). The importance behind the school connectedness is that connection to a school gives young adolescents a feeling that they belong to their school, and that their teachers and peers care about them and their learning process (Centers for Disease Control and Prevention 2009). Nowadays, children spend more time in school with their teachers and their peers than they spend with their parents due to overload and work pressure. We assume that feeling accepted and cared about in the environment in which they spend a great amount of time is becoming more and more important in young people's lives, enhancing their resilience and protecting them against substance use. To some extent, school connectedness may serve as a social control that reduces risk behavior or prevents it (CATALANO et al. 2004).

As mentioned in the introduction, the key protective role of home environments lies in early childhood when intrapersonal and interpersonal skills develop and create a primary shield against risk behavior. As the children get older, the importance shifts away from their home environment and this process culminates in adolescence. Attachment and influence moves from parents to peers as a separation process emerges, and peers become the resource of free time activity and comfort (NoLLER et al. 2000). Our results support this theory, showing that both higher perceived home support and higher perceived prosocial peers play a key role in those interviewed becoming non-users rather than permanent users. Home support still plays a role as a protective factor but not exclusively. We could hypothesize that in early adolescence, the shift from home attachment to peer attachment begins but their complementary role has a greater protective effect than when taken individually. The significance of peer importance in our results is obvious. The lower the level of perceived prosocial peers, the higher probability of not only becoming permanent users but also a new user. It is known that adolescents tend to pick friends with similar attitudes, values, and background (VON TETZCHNER 2018), and therefore it may be possible that the protective effect of their home environment manifests its protective role through the friends with whom the child chooses to associate with.

Our results have indicated that community environment is not associated with substance use among young adolescents. Community environment can be seen as a protective factor among collectivistic cultures to a greater extent when compared to individualistic cultures. Research in specific demographic groups where substance 
use tends to be high, such as American Indian and Alaska Natives (RADIN et al. 2015), supports this idea and focuses the attention to community resilience. In short, we could imply that a risky environment contributes to early adolescents' substance use whereas a safe environment is not an eminent protective factor against the early onset of substance use.

In our study, we also investigated the role of gender and program participation regarding substance use among early adolescence. A direct effect of the program participation on substance use was found, particularly participation in Unplugged: it lowered the chances of being a new user compared to our control group, which suggests that Unplugged has a protective effect against the early onset of substance use. These results are in accordance with the main goal of primary prevention programs (CUIJPERS 2003) and also in accordance with the goal of Unplugged - not to just reduce substance use but also to delay its onset to later years where young people would be more mature to handle the situation correctly. In this study, being a female increases the probability of being a non-user adolescent when compared to males. This result supports a previous finding that males tend to engage in risk behavior at an earlier age than females (Alvanzo et al. 2011). However, in recent years, more research has suggested that although gender differences are present during the early adolescence, among 13 and 15-year-old adolescents, the differences are ceasing to exist (WHO 2016).

To conclude, our research generally confirms the resilience theory by showing that the combination of various internal and perceived external resilience factors (i.e., self-esteem, school connectedness, home support, prosocial peers) emerging from the social areas and relationships, play an important role in maintaining healthy behavior and provide protection from engaging in alcohol use or cigarette smoking in early adolescence. However, school psychologists and educators remain limited in their opportunities to intervene and secure, for example, efficient home support or community environment in order to promote resilience. On the other hand, they may be very efficient in the school context. It seems that school carries an opportunity to promote resilience by creating an environment where students feel connected and have prosocial peers. VAN UDEN (2014) asked schoolchildren what it is that teachers do to help them build resilience, and two aspects of teachers' behavior were identified: (1) helpful, friendly and firm behavior, (2) authoritative management. JOHNSON (2008) has also emphasized the daily interaction between student and teacher. It was the 'little things' which make students engaged, persistent, and gives them the feeling of self-worth such as a student being listened to, providing help with schoolwork, behaving respectfully, and maintaining hope and encouragement regarding student learning. Moreover, schools provide a place for school-based prevention programs such as Unplugged, of which the effectiveness in preventing engagement in risk behavior has been shown. Therefore, we recommend participation in the evidence-based school-centered intervention programs. 
It is important to acknowledge the limitations of this study. Early adolescents are a specific group for investigation, characterized by developmental changes, therefore any generalization from this study should be done with care. Secondly, the time period in which we collected our data was relatively short. We have addressed the changes only within six months. It would be beneficial to study the predictive power over a longer period of adolescent years. Future studies should also focus on other internal assets linked to substance use such as self-efficacy, optimism, coping, etc. Lastly, to assess substance use, internal assets and perceived external resources of resilience can be limited to some extent due to reliance on the self-reporting of early adolescents, knowing only their perception of their environment, and their internal assets.

\section{Conclusion}

In summary, this study reports on the importance of internal assets and external resources of resilience, the program Unplugged and gender regarding absence of alcohol or cigarette use in early age. We have found that early adolescents who have higher levels of self-esteem, perceived home support, school connectedness, prosocial peers and are female, were more likely not to use any alcohol and cigarettes in the previous 30 days within a six month period. Early adolescents with higher levels of prosocial peers were also less likely to become new users. Participation in the school-based universal prevention program Unplugged had a potential for delaying an early onset of substance use - the probability of becoming a new user was higher in the control group than in the experimental group. Despite these limitations, this study provides a unique contribution to the growing theoretical and practical knowledge regarding resilience, prevention programs, and substance use in early adolescence.

\section{References}

Alesina, M., F. Vigna-Taglianti, G.Cuomo, S. Talić \& M. Košir (2014, October 22-24) Evaluation of Effectiveness of Unplugged in Slovenia: a Non-Randomized Controlled Trial [Conference presentation], European Society for Prevention Research 6th Conference, Ljubljana, Slovenia, retrieved 18 Sep from https://www.eudap.net/PDF/201510c_EUSPR_Unplugged\%20effectiveness\%20 in\%20Slovenia.pdf.

Alvanzo, A.A.H., C.L. Storr, L. La flair, K.M. Green, F.A. Wagner \& R.M. CRUm (2011) 'Race/Ethnicity and Sex Differences in Progression from Drinking Initiation to the Development of Alcohol Dependence', Drug and Alcohol Dependence 118(2-3), 375-82 (https://doi.org/10.1016/j.drugalcdep.2011.04.024). 
Benard, B. (2004) Resiliency: What We Have Learned (San Francisco: WestEd).

Benard, B. \& S. Slade (2009) 'Listening to Students: Moving from Resilience

Research to Youth Development Practice and School Connectedness' in M.J. Furlong, R.Gilman \& E. S.Heubner, eds., Handbook of Positive Psychology in Schools, 353-69 (New York: Routledge) retrieved 14 Sep 2021 from https:// citeseerx.ist.psu.edu/viewdoc/download?doi=10.1.1.404.4872\&rep=rep1\&type $=$ pdf.

Berinšterová, M., A. JanovskÁ, B. Gajdošová, O. Kalina \& M. BačíKovÁ (2015) Health-Related Behavior among Schoolchildren: Unplugged-Drug Use Prevention Program in Slovakia (Košice: Univerzita Pavla Jozefa Šafária v Košiciach) retrieved 14 Sep 2021 from https:/www.upjs.sk/public/media/13643/Health-related\%20behavior\%20among\%20schoolchildren.pdf.

Bohrn, K., L. Fabiani, E. Florek, R. Gabrhelik, R. Galanti, M. Kyriakidou, S. Sanchez, G. Terzopoulou, S. Vadrucci, M. Vassara \& F. V. Taglianti (2008) 'Preventing Substance Abuse among Students: A Guide to Successful Implementation of Comprehensive Social Influence (CSI) Curricula in Schools' in European Drug Addiction Prevention Trial, retrieved 18 Sep 2021 from https:// www.eudap.net/Unplugged_HomePage.aspx.

Bronfenbrenner, U. (1979) The Ecology of Human Development: Experiments by Nature and Design (Cambridge, USA: Harvard).

Cadima, J., M. Enrico, T. Ferreira, K. Verschueren, T. Leal \& P.M Matos (2016) 'Self-Regulation in Early Childhood: The Interplay Between Family Risk, Temperament and Teacher-Child Interactions', European Journal of Developmental Psychology 13(3), 341-60 (https://doi.org/10.1080/17405629. 2016.1161506).

Castellanos-Ryan, N., M. O’leary-Barrett \& P.J. Conrod (2013) 'Substance-Use in Childhood and Adolescence: A Brief Overview of Developmental Processes and Their Clinical Implications', Journal of the Canadian Academy of Child and Adolescent Psychiatry 22(1), 41-46.

Catalano, R.F., S. Oesterle, C.B. Fleming \& J.D. Hawkins (2004) 'The Importance of Bonding to School for Healthy Development: Findings from the Social Development Research Group', Journal of School Health 74(7), 252-61 (http:// doi.org/10.1111/j.1746-1561.2004.tb08281.x).

Centers For Disease Control And Prevention (2009) School Connectedness: Strategies for Increasing Protective Factors Among Youth (Atlanta: US Department of Health and Human Services) retrieved 15 Aug 2020 from https://www.cdc. gov/healthyyouth/protective/pdf/connectedness.pdf.

Constantine, N., B. Benard \& M. Diaz (1999) Measuring Protective Factors and Resilience Traits in Youth: The Healthy Kids Resilience Assessment, Paper presented at the Seventh Annual Meeting of the Society for Prevention Research, New Orleans, LA. 
Cuijpers, P. (2003) 'Three Decades of Drug Prevention Research', Drugs: Education, Prevention and Policy 10(1), 7-20 (https://doi.org/10.1080/096876302100001 8900).

Diclemente, R.J., W.B. Hansen \& L.E. Ponton, eds. (2013) Handbook of Adolescent Health Risk Behavior (Berlin: Springer).

Donnelly, J., M. Young, R. Pearson, T.M. Penhollow \& A. Hernandez (2008) 'Area Specific Self-Esteem, Values, and Adolescent Substance Use', Journal of Drug Education 38(4), 389-403 (http://doi.org/10.2190/DE.38.4.f).

ESPAD Group (2016) ESPAD Report 2015: Results from the European School Survey Project on Alcohol and Other Drugs (Luxembourg: Publications Office of the European Union) retrieved 15 Sep 2021 from https://www.emcdda.europa.eu/ system/files/publications/3074/ESPAD_report_2015.pdf.

Faggiano, F., F. Vigna-Taglianti, G. Burkhart, K. Bohrn, L. Cuomo, D. Gregori, M. Panella, M. Scatigna, R. Siliquini, L. Varona, P. Van der Kreeft, M. Vassara, G. Wiborg, M.R. Galanti \& the EU-Dap Study Group (2010) 'The Effectiveness of a School-Based Substance Abuse Prevention Program: 18-Month Follow-Up of the EU-Dap Cluster Randomized Controlled Trial', Drug and Alcohol Dependence 108(1-2), 56-64 (http://doi.org/10.1016/j. drugalcdep.2009.11.018).

Fergus, S. \& M.A Zimmerman (2005) 'Adolescent Resilience: A Framework for Understanding Healthy Development in the Face of Risk', Annual Review of Public Health 26, 399-419 (http://doi.org/10.1146/annurev.publhealth.26.021304.144357).

FIELD, A. (2009) Discopering Statistics Using SPSS (3 ${ }^{\text {rd }}$ ed., Thousand Oaks: SAGE). Finkenauer, C., R.C.M. Engels \& R.F. Baumeister (2005) 'Parenting Behaviour and Adolescent Behavioural and Emotional Problems: The Role of Self-Control', International Journal of Behavioral Development 29(1), 58-69 (https://doi. org/10.1080/01650250444000333).

Furlong, M. J., K.M. Ritchey \& L.M. O’Brennan (2009) 'Developing Norms for the California Resilience Youth Development Module: Internal Assets and School Resources Subscales', The California School Psychologist 14, 35-46 (https://doi.org/10.1007/BF03340949).

Gabrhelik, R., A.Duncan, M.H. Lee, L. Stastna, C.D.M. Furr-Holden \& M. Miovsky (2012) 'Sex Specific Trajectories in Cigarette Smoking Behaviors among Students Participating in the Unplugged School-Based Randomized Control Trial For Substance Use Prevention', Addictive Behaviors 37(10), 1145-50 (http://doi.org/10.1016/j.addbeh.2012.05.023).

Gaertner, A.E., P.J. Fite \& C.R. Colder (2010) 'Parenting and Friendship Quality as Predictors of Internalizing and Externalizing Symptoms in Early Adolescence', Journal of Child and Family Studies 19, 101-108 (https://doi.org/10.1007/ s10826-009-9289-3). 
Griffin, K.W. \& G.J. Botvin (2010) 'Evidence-Based Interventions for Preventing Substance Use Disorders in Adolescents', Child and Adolescent Psychiatric Clinics of North America 19(3), 505-26 (http://doi.org/10.1016/j.chc.2010.03.005). Hanson, T.L. \& J.O. Kim (2007) 'Measuring Resilience and Youth Development: The Psychometric Properties of the Healthy Kids Survey', Issues \& Answers Report REL 2007, 34 (Washington: National Center for Education Evaluation and Regional Assistance) retrieved 15 Sep 2021 from https://ies.ed.gov/ncee/ edlabs/regions/west/pdf/REL_2007034.pdf.

Hodder, R.K., M. Freund, J. Bowman, L. Wolfenden, K. Gillham, J. Dray \& J. Wiggers (2016) 'Association Between Adolescent Tobacco, Alcohol and Illicit Drug Use and Individual and Environmental Resilience Protective Factors', BMJ Open 6(11) e012688 (http://doi.org/10.1136/bmjopen-2016-012688).

Institute of Medicine (US) and National Research Council (US) Committee on the Science of Adolescence (2011) The Science of Adolescent Risk-Taking: Workshop Report (Washington: The National Academies) retrieved 15 Sep 2021 from https://www.ncbi.nlm.nih.gov/books/NBK53418/.

Johnson, B. (2008) 'Teacher-Student Relationships which Promote Resilience at School: A Micro-Level Analysis of Students' Views', British Journal of Guidance \& Counselling 36(4), 385-98 (https://doi.org/10.1080/03069880802364528).

King, K.M. \& L. Chassin (2007) 'A Prospective Study of the Effects of Age of Initiation of Alcohol and Drug Use on Young Adult Substance Dependence', Journal of Studies on Alcohol and Drugs 68(2), 256-65 (http://doi. org/10.15288/jsad.2007.68.256).

Kokkevi, A., E. Kanavou, C. Richardson, A. Fotiou, S. Papadopoulou, K. Monshouwer, J. Matias \& D. Olszewski (2014) 'Polydrug Use by European Adolescents in the Context of Other Problem Behaviours', Nordic Studies on Alcohol and Drugs 31(4), 323-42 (https://doi.org/10.2478/nsad-2014-0026).

Kung, E.M. \& A.D. Farrell (2000) 'The Role of Parents and Peers in Early Adolescent Substance Use: An Examination of Mediating and Moderating Effects', Journal of Child and Family Studies 9, 509-28 (https://doi. org/10.1023/A:1009427010950).

Lipperman-Kreda, S., P.J. Gruenewald, J.W. Grube. \& M. Bersamin (2017) 'Adolescents, Alcohol, and Marijuana: Context Characteristics and Problems Associated with Simultaneous Use', Drug and Alcohol Dependence 179, 55-60 (http://doi.org/10.1016/j.drugalcdep.2017.06.023).

Luthar, S.S., D. Cicchetti \& B. Becker (2000) 'The Construct of Resilience: A Critical Evaluation and Guidelines for Future Work', Child Development 71(3), 543-62 (https://doi.org/10.1111/1467-8624.00164).

Masten, A.S. (2007) 'Resilience in Developing Systems: Progress and Promise as the Fourth Wave Rises', Development and Psychopathology 19(3), 921-30 (http://doi.org/10.1017/S0954579407000442). 
Masten, A.S. (2014) 'Global Perspectives on Resilience in Children and Youth', Child Development 85(1), 6-20 (http://doi.org/10.1111/cdev.12205).

Miovský, M., P. Novak, L. Stastna, R. Gabrhelik, L. Jurystova \& J. Vopravil (2012) 'The Effect of the School-Based Unplugged Preventive Intervention on Tobacco Use in the Czech Republic', Adicciones 24(3), 211-17.

Moffitt, T.E., L. Arseneault, D. Belsky, N. Dickson, R.J. Hancox, H. Harrington, R. Houts, R. Poulton, B.W. Roberts, S.Ross, M.R. Sears, W.M. Thomson \& A. CASPI (2011) 'A Gradient of Childhood Self-Control Predicts Health, Wealth, and Public Safety', Proceedings of the National Academy of Sciences 108(7), 2693-98 (http://doi.org/10.1073/pnas.1010076108).

Noller, P., J. Feeney, C. Peterson (2000) Personal Relationships Across the Lifespan ( $1^{\text {st }}$ ed., New York: Routledge).

Nowak, M., M. Papiernik, A. Mikulska \& B. Czarkowska-Paczek (2018) 'Smoking, Alcohol Consumption, and Illicit Substances Use Among Adolescents in Poland', Substance Abuse Treatment, Prevention, and Policy 13, 42 (https:// doi.org/10.1186/s13011-018-0179-9).

OsGood, D.W., J.K. Wilson, P.M. O’malley, J.G. Bachman \& L.D. Johnston (1996) 'Routine Activities and Individual Deviant Behavior', American Sociological Review 61(4), 635- 55 (https://doi.org/10.2307/2096397).

Poudel, A. \& Gautam, S. (2017) 'Age of Onset of Substance Use and Psychosocial Problems Among Individuals with Substance Use Disorders', BMC Psychiatry 17, 10 (https://doi.org/10.1186/s12888-016-1191-0).

Radin, S.M., S.H. Kutz, J. La Marr, D. Vendiola, M. Vendiola, B. Wilbur, L.R. Thomas \& D.M. Donovan (2015) 'Community Perspectives on Drug/ Alcohol Use, Concerns, Needs, and Resources in Four Washington State Tribal Communities', Journal of Ethnicity in Substance Abuse 14(1), $29-58$ (https:// doi.org/10.1080/15332640.2014.947459).

Richardson, C.G., J.Y. KwON \& P.A. Ratner (2013) 'Self-Esteem and the Initiation of Substance Use Among Adolescent', Canadian Journal of Public Health 104, e60 - e63 (https://doi.org/10.1007/BF03405656).

Rosenberg, M. (1979) Conceiving the Self (New York: Basic Books).

Rudzinski, K., P. Mcdonough, R. Gartner \& C. Strike (2017) 'Is There Room for Resilience? A Scoping Review and Critique of Substance Use Literature and its Utilization of the Concept of Resilience', Substance Abuse Treatment, Prevention, and Policy 12, 41 (https://doi.org/10.1186/s13011-017-0125-2).

Sanchez, Z.M., A. Sanudo, S. Andreoni, D. Schneider, A.P.D. Pereira \& F. Faggiano (2016) 'Efficacy Evaluation of the School Program Unplugged for Drug Use Prevention Among Brazilian Adolescents', Bmc Public Health 16, 1206 (http://doi.org/10.1186/s12889-016-3877-0).

Ungar, M. (2004) Nurturing Hidden Resilience in Troubled Youth (Toronto: University of Toronto). 
VAN BREDA, A.D. (2018) 'A Critical Review of Resilience Theory and its Relevance for Social Work', Social Work 54(1), 1-18 (https://doi.org/10.15270/54-1-611).

van Uden, J.M., H. Ritzen \& J. M. Pieters (2014) 'Engaging Students: The Role of Teacher Beliefs and Interpersonal Teacher Behavior in Fostering Student Engagement in Vocational Education', Teaching and Teacher Education 37, 21-32 (http://doi.org/10.1016/j.tate.2013.08.005).

von Tetzchner, S. (2018) Child and Adolescent Psychology: Typical and Atypical Development (London: Routledge).

Weatherson, K.A., M. O’neill, E.Y. Lau, W. Qian, S.T. Leatherdale \& G.E. FAULKNER (2018) 'The Protective Effects of School Connectedness on Substance Use and Physical Activity', Journal of Adolescent Health 63(6), 724-31 (http:// doi.org/10.1016/j.jadohealth.2018.07.002).

Wills, T.A., M.G. Ainette, M. Stoolmiller, F.X. Gibbons \& O. Shinar (2008) 'Good Self-Control as a Buffering Agent for Adolescent Substance Use: An Investigation in Early Adolescence with Time-Varying Covariates', Psychology of Addictive Behaviors 22(4), 459-71 (https://doi.org/10.1037/a0012965).

World Health Organization (2013) Enforcing Bans on Tobacco Advertising, Promotion and Sponsorship: WHO Report on the Global Tobacco Epidemic (Geneva: WHO) retrieved 15 Sep 2021 from https:/apps.who.int/iris/bitstream/ handle/10665/85380/9789241505871_eng.pdf;jsessionid=4AB5FBAEB9E2BB1005A A70A10850B8F8? sequence $=1$.

World Health Organization (2016) 'Growing Up Unequal: Gender and Socioeconomic Differences in Young People's Health and Well-Being', Healthy Policy for Children and Adolescents, No.7 (Geneva: WHO) retrieved 15 Sep 2021 from https://www.euro.who.int/_data/assets/pdf_file/0003/303438/HSBC-No.7Growing-up-unequal-Full-Report.pdf.

Zamboanga, B.L., S.J. Schwartz, L.H. Jarvis \& K. VAn Tyne (2009) 'Acculturation and Substance Use Among Hispanic Early Adolescents: Investigating the Mediating Roles of Acculturative Stress and Self-Esteem', The Journal of Primary Prevention 30, 315-33 (https://doi.org/10.1007/s10935-009-0182-z). 